\title{
Analisis Pengaruh Dimensi Kualitas Pelayanan terhadap Kepuasan Pasien Peserta BPJS Kesehatan di Instalasi Rawat Jalan RSUD dr. H. Soewondo Kendal
}

\author{
Nur Widyastuti*, Bagoes Widjanarko**, Mateus Sakundarno Adi** \\ * Staf Dinas Kesehatan Kabupaten Kendal, **Staf Pengajar Program Magister Ilmu Kesehatan \\ Masyarakat \\ Universitas Diponegoro \\ Email:nurw76@gmail.com
}

\section{ABSTRACT:}

This research aims to figure out whether or not dimension of service quality namely tangible, reliability, responsiveness, assurance, and empathy has influence on the satisfaction of outpatients whose member of BPJS Kesehatan on polyclinic at $d r . H$. Soewondo Hospital Kendal.

The design of this research was cross sectional with quantitative approach. The population of this research was the outpatients whose member of BPJS Kesehatan on polyclinic at $d r$. H. Soewondo Hospital Kendal, and the subject of research was the patients who visit and get treatment in this polyclinic 2 to 3 times by utilizing health insurance facility BPJS. The data was collected by using non-probability sampling technique. Then, Smart PLS analysis was used for processing and analyzing the data. Total sampling was 100 respondents by using purposive sampling to get them.

The research result according to Smart PLS shows that tangible dimension gives positive influence significantly on the patients satisfaction with t-test value 3,043 > 1,96, the reliability influences significantly with t-test value 2,571 > 1,96, responsiveness gives positive influence significantly with $t$ test value 3,101 > 1,96. Emphaty dimension also gives positive influence significantly with t-test value 3,469 > 1,96. While assurance dimension does not influence the patients satisfaction with t-test value 1,491< 1,96. This test result states that not all variables of the service quality influence the patients'satisfaction.

The conclusion of this research is the service quality influence the patients' satisfaction in Outpatients whose member of BPJS Kesehatan at polyclinic RSUD $d r$. H. Soewondo Kendal and the dimension of tangible, reliability, responsiveness and emphaty give positive influence on the patients' satisfaction, while the dimension of assurance do not give influence on the patients'satisfaction.

Keywords : Service Quality, Tangible, Reliability, Responsiveness, Assurance, Empathy, Patients' Satisfaction, Member of BPJS Kesehatan 


\section{PENDAHULUAN}

Rumah Sakit (RS) adalah sarana pelayanan kesehatan yang dapat di selenggarakan oleh pemerintah dan swasta adalah. RS melayani masyarakat dengan pelayanan kesehatan meliputi kegiatan pelayanan rawat jalan, rawat inap dan rawat darurat yang terdiri dari pelayanan medik dan penunjang medik. ${ }^{1}$ RSUD dr. H. Soewondo Kendal adalah RS pemerintah yang menjadi salah satu RS rujukan pasien peserta BPJS Kesehatan di Kabupaten Kendal. Sebelumnya RSUD dr. H. Soewondo Kendal adalah satu-satunya RS rujukan bagi peserta ASKES PNS. Pilihan RS yang lain bagi peserta BPJS di Kabupaten Kendal adalah RS Swasta yaitu RS Islam Weleri Kendal yang baru tahun 2014 ini melayani peserta BPJS. Selain itu juga terdapat RSUD dr. H. Adhyatma Tugurejo dan RS Permata Medika Ngaliyan Semarang di daerah perbatasan Kabupaten Kendal. Dengan adanya kompetitor maka RSUD dr. H. Soewondo Kendal dituntut untuk meningkatkan kualitas pelayanan kesehatan khususnya bagi pasien peserta BPJS.

Hasil survey indeks kepuasan masyarakat tahun 2015 di RSUD dr. H. Soewondo menunjukkan bahwa terdapat unit pelayanan di RSUD dr.H. Soewondo Kendal yang masih perlu ditingkatkan yaitu unit Rawat Jalan, dimana dari jawaban masyarakat dengan persebaran persentase hampir sama yang menyatakan waktu tunggu pelayanan puas $(50,3 \%)$ dan yang tidak puas $(49,7 \%) .^{2}$ RSUD dr. H. Soewondo belum pernah mengadakan survey khusus untuk mengukur kepuasan pasien peserta BPJS Kesehatan.

Dalam rangka menghadapi persaingan yang makin kompetitif Rumah sakit harus berorientasi dengan kepuasan pelanggan atau pasien. Pasien akan loyal dengan rumah sakit dan tidak akan beralih kepada rumah sakit lain apabila kualitas pelayanan dianggap memuaskan dan sesuai dengan harapannya. Kotler dan Keller (2009) menyebutkan bahwa terdapat lima indikator kualitas jasa, yaitu tangibles (bentuk nyata/berwujud), reliability (kehandalan), responsiveness (daya tanggap), assurance (jaminan) dan emphaty ( empati). ${ }^{3}$ Dengan melakukan penilaian atas lima indikator tersebut maka akan dapat melihat bagaimana kepuasan pasien peserta BPJS yang menggunakan jasa pelayanan RSUD dr. $\mathrm{H}$. Soewondo Kendal.

\section{METODE PENELITIAN}

Penelitian ini merupakan penelitian kuantitatif dengan metode cross sectional. Populasi penelitian adalah pasien peserta BPJS Kesehatan di instalasi rawat jalan RSUD dr. H. Soewondo Kendal, sedangkan sampelnya adalah pasien rawat jalan RSUD dr. H. Soewondo Kendal yang telah periksa minimal 2-3 kali dengan menggunakan kartu BPJS Kesehatan. Pengumpulan data menggunakan cara Non Probability Sampling. Data diolah dan dianalisis memakai analisis Smart PLS . Besar sampel sejumlah 100 orang responden dan menggunakan teknik Purposive Sampling untuk pengambilan sampel. Variabel bebas adalah tangible, reliability, responsiveness, assurance, dan empathy. Sedangkan variabel terikat adalah kepuasan. Analisis data menggunakan Smart PLS.

\section{HASIL DAN PEMBAHASAN \\ Hasil \\ ANALISIS DATA}

1. Analisis Deskriptif Profil Responden.

Berdasarkan hasil penelitian yang dilakukan terhadap 100 orang responden di RSUD dr. H. Soewondo Kendal 
melalui wawancara dan kuesioner.

Tabel 1 Profil Responden di Instalasi Rawat Jalan RSUD dr. H. Soewondo Kendal

\begin{tabular}{|c|c|c|c|}
\hline No & Deskripsi & $\begin{array}{c}\text { Jumlah } \\
\text { Responden }\end{array}$ & $\begin{array}{c}\text { Persen } \\
\text { tase } \\
(\%)\end{array}$ \\
\hline \multirow[t]{4}{*}{1.} & Jenis Kelamin & & \\
\hline & Laki-laki & 32 & 32.0 \\
\hline & Perempuan & 68 & 68.0 \\
\hline & Jumlah & 100 & 100 \\
\hline \multirow[t]{5}{*}{2.} & Umur: & & \\
\hline & $<25$ tahun & 12 & 12.0 \\
\hline & $25-35$ tahun & 13 & 13.0 \\
\hline & $>35$ tahun & 75 & 75.0 \\
\hline & Jumlah & 100 & 100 \\
\hline No & Deskripsi & $\begin{array}{c}\text { Jumlah } \\
\text { Responden }\end{array}$ & $\begin{array}{c}\text { Persen } \\
\text { tase } \\
(\%)\end{array}$ \\
\hline \multirow[t]{6}{*}{3.} & $\begin{array}{l}\text { Pendidikan : } \\
\text { Tidak } \\
\text { Sekolah/Tidak }\end{array}$ & 12 & 12.0 \\
\hline & Lulus SD & 28 & 28.0 \\
\hline & SD sederajat & 30 & 30.0 \\
\hline & SLTP sederajat & 23 & 23.0 \\
\hline & $\begin{array}{l}\text { SLTA sederajat } \\
\text { PT }\end{array}$ & 7 & 7.0 \\
\hline & Jumlah & 100 & 100 \\
\hline
\end{tabular}

Sumber : Data Primer, diolah 2018

a. Analisis Deskriptif Variabel Penelitian

Gambaran mengenai variabel-variabel penelitian disajikan dalam tabel statistik deskriptif masing-masing variabel yang menunjukkan persentase skala sikap responden dan nilai rata-rata .

1) Tanggapan responden tentang dimensi pelayanan tangible.

Tabel 2 Tanggapan responden tentang dimensi pelayanan tangible

\begin{tabular}{ccccccc}
\hline code & $\begin{array}{c}\text { STS } \\
(\%)\end{array}$ & $\begin{array}{c}\text { TS } \\
(\%)\end{array}$ & $\begin{array}{c}\text { N } \\
(\%)\end{array}$ & $\begin{array}{c}\text { S } \\
(\%)\end{array}$ & $\begin{array}{c}\text { SS } \\
(\%)\end{array}$ & $\begin{array}{c}\text { Rata- } \\
\text { rata }\end{array}$ \\
\hline $\mathrm{T} 1$ & 0,0 & 3,0 & 21,0 & 54,0 & 22,0 & 3,95 \\
\hline $\mathrm{T} 2$ & 1,0 & 3,0 & 14,0 & 61,0 & 21,0 & 3,98 \\
\hline
\end{tabular}

\begin{tabular}{ccccccc}
\hline ode & $\begin{array}{c}\text { STS } \\
(\%)\end{array}$ & $\begin{array}{c}\text { TS } \\
(\%)\end{array}$ & $\begin{array}{c}\text { N } \\
(\%)\end{array}$ & $\begin{array}{c}\text { S } \\
(\%)\end{array}$ & $\begin{array}{c}\text { SS } \\
(\%)\end{array}$ & $\begin{array}{c}\text { Rata- } \\
\text { rata }\end{array}$ \\
\hline T3 & 3,0 & 5,0 & 29,0 & 54,0 & 9,0 & 3,61 \\
\hline T4 & 1,0 & 1,0 & 4,0 & 61,0 & 33,0 & 4,24 \\
\hline T5 & 0,0 & 5,0 & 30,0 & 53,0 & 12,0 & 3,72 \\
\hline T6 & 0,0 & 0,0 & 42,0 & 56,0 & 2,0 & 3,60 \\
\hline T7 & 0,0 & 0,0 & 16,0 & 70,0 & 14,0 & 3,98 \\
\hline T8 & 0,0 & 0,0 & 12,0 & 71,0 & 17,0 & 4,05 \\
\hline \multicolumn{6}{c}{ Rata-rata Total } \\
\hline
\end{tabular}

Sumber : Data Primer diolah, 2018

Keterangan :

$\mathrm{T} 1$ : Kebersihan ruang tunggu

T2 : Ketersediaan media TV

T3 : Kecukupan tempat duduk

T4 : Penampilan petugas

T5 : Fungsi alat antrian

T6 : Kebersihan Toilet

T7 : Ketersediaan pengatur udara (AC)

T8 : Kejelasan petunjuk/informasi

2) Tanggapan responden terhadap dimensi pelayanan reliability.

Tabel 3 Tanggapan responden terhadap dimensi pelayanan reliability

\begin{tabular}{ccccccc}
\hline Kode & $\begin{array}{c}\text { STS } \\
(\%)\end{array}$ & $\begin{array}{c}\text { TS } \\
(\%)\end{array}$ & $\begin{array}{c}\text { N } \\
(\%)\end{array}$ & $\begin{array}{c}\text { S } \\
(\%)\end{array}$ & $\begin{array}{c}\text { SS } \\
(\%)\end{array}$ & $\begin{array}{c}\text { Rata- } \\
\text { rata }\end{array}$ \\
\hline REL1 & 0,0 & 0,0 & 25,0 & 73,0 & 2,0 & 3,77 \\
\hline REL2 & 0,0 & 1,0 & 26,0 & 61,0 & 12,0 & 3,84 \\
\hline REL3 & 0,0 & 0,0 & 23,0 & 71,0 & 6,0 & 3,83 \\
\hline REL4 & 0,0 & 0,0 & 12,0 & 79,0 & 9,0 & 3,97 \\
\hline REL5 & 0,0 & 1,0 & 4,0 & 47,0 & 48,0 & 4,42 \\
\hline REL6 & 0,0 & 0,0 & 22,0 & 68,0 & 10,0 & 3,88 \\
\hline \multicolumn{6}{c}{ Rata -rata total } \\
\hline
\end{tabular}

Sumber : Data Primer diolah, 2018

Keterangan :

REL1 : Keramahan petugas pendaftaran

REL2 : Ketepatan waktu kedatangan dokter

REL3 : Keramahan perawat

REL4 : Tidak ada diskriminasi pasien

REL5 : Kerahasiaan medis

REL6 : Kecekatan petugas 
3) Tanggapan responden tentang dimensi pelayanan responsiveness.

Tabel 4 Tanggapan responden tentang dimensi pelayanan responsiveness

$\begin{array}{llllll}\text { Kode } & \text { TS } & \text { N } & \text { S } & \text { SS } & \text { Rata- }\end{array}$

$(\%) \quad(\%) \quad(\%) \quad(\%) \quad(\%) \quad$ rata

$\begin{array}{lllllll}\text { RES1 } & 0,0 & 0,0 & 25,0 & 71,0 & 4,0 & 3,79\end{array}$

$\begin{array}{lllllll}\text { RES2 } & 0,0 & 0,0 & 28,0 & 67,0 & 5,0 & 3,77\end{array}$

$\begin{array}{lllllll}\text { RES3 } & 0,0 & 0,0 & 5,0 & 56,0 & 39,0 & 4,34\end{array}$

$\begin{array}{lllllll}\text { RES4 } & 0,0 & 0,0 & 19,0 & 70,0 & 11,0 & 3,92\end{array}$

$\begin{array}{lllllll}\text { RES5 } & 0,0 & 0,0 & 23,0 & 67,0 & 10,0 & 3,87\end{array}$

Rata - rata total 3,94

Sumber : Data Primer diolah, 2018

Keterangan :

RES1 : Ketanggapan petugas pendaftaran

RES2 : Perhatian perawat

RES3 : Ketanggapan dokter

RES4 : Informasi aktif oleh petugas

RES5 : Ketanggapan perawat

4) Tanggapan responden tentang dimensi pelayanan assurance.

Tabel 5 Tanggapan responden tentang dimensi pelayanan assurance.

Kode STS TS N $\quad$ S $\quad$ SS Rata$(\%) \quad(\%) \quad(\%) \quad(\%) \quad(\%) \quad$ rata

\begin{tabular}{lllllll}
\hline A1 & 0,0 & 0,0 & 23,0 & 71,0 & 6,0 & 3,83 \\
\hline A2 & 0,0 & 0,0 & 37,0 & 61,0 & 2,0 & 3,65 \\
\hline A3 & 0,0 & 0,0 & 16,0 & 52,0 & 32,0 & 4,16 \\
\hline A4 & 0,0 & 0,0 & 12,0 & 78,0 & 10,0 & 3,98 \\
\hline A5 & 0,0 & 0,0 & 15,0 & 51,0 & 34,0 & 4,19 \\
\hline A6 & 0,0 & 0,0 & 10,0 & 54,0 & 36,0 & 4,26 \\
\hline \multicolumn{6}{c}{ Rata - rata total }
\end{tabular}

Sumber : Data Primer diolah, 2018

Keterangan :

A1 : Tidak ada diskriminasi status pasien

A2 : Pengecekan nama pasien dengan benar

A3 : Ketepatan jadwal dokter spesialis

A4 : Kejelasan penjelasan petugas

A5 : Perilaku petugas

A6 : Kerahasiaan pasien dijaga
4 ) Tanggapan responden tentang dimensi pelayanan empathy.

Tabel 6 Tanggapan responden tentang dimensi pelayanan empathy.

Kode $\begin{array}{llllll}\text { STS } & \text { TS } & \mathrm{N} & \mathrm{S} & \mathrm{SS} & \text { Rata- }\end{array}$ $(\%) \quad(\%) \quad(\%) \quad(\%) \quad(\%) \quad$ rata

\begin{tabular}{ccccccc}
\hline E1 & 0,0 & 0,0 & 18,0 & 72,0 & 10,0 & 3,92 \\
\hline E2 & 0,0 & 0,0 & 30,0 & 61,0 & 9,0 & 3,79 \\
\hline E3 & 0,0 & 0,0 & 2,0 & 58,0 & 40,0 & 4,38 \\
\hline E4 & 0,0 & 0,0 & 14,0 & 74,0 & 12,0 & 3,98 \\
\hline E5 & 0,0 & 0,0 & 42,0 & 51,0 & 7,0 & 3,65 \\
\hline \multicolumn{7}{c}{ Rata - rata total }
\end{tabular}

Sumber : Data Primer diolah, 2018

Keterangan :

E1 : Perhatian petugas pendaftaran

E2 : Perhatian perawat

E3 : Perhatian dokter

E4 : Wawancara dokter

E5 : Keramahan petugas

5) Tanggapan responden tentang variabel kepuasan.

Tabel 7 Tanggapan responden tentang variabel kepuasan.

Kode STS TS N $\quad$ S $\quad$ SS Rata$(\%) \quad(\%) \quad(\%) \quad(\%) \quad(\%) \quad$ rata

\begin{tabular}{lllllll}
\hline P1 & 1,0 & 4,0 & 30,0 & 62,0 & 3,0 & 3,62 \\
\hline P2 & 0,0 & 0,0 & 30,0 & 63,0 & 7,0 & 3,77 \\
\hline P3 & 0,0 & 0,0 & 14,0 & 73,0 & 13,0 & 3,99 \\
\hline P4 & 0,0 & 0,0 & 11,0 & 80,0 & 9,0 & 3,98 \\
\hline P5 & 0,0 & 1,0 & 12,0 & 45,0 & 42,0 & 4,28 \\
\hline P6 & 0,0 & 0,0 & 11,0 & 68,0 & 21,0 & 4,10 \\
\hline \multicolumn{7}{c}{ Rata - rata total }
\end{tabular}

Sumber : Data Primer diolah, 2018

Keterangan :

P1 : Lama waktu tunggu

P2 : Sikap petugas

P3 : Biaya pelayanan

P4 : Informasi petugas

P5 : Fasilitas rumah sakit

P6 : Perawatan petugas 
b. Analisis Inferensial Variabel Penelitian

Pengujian hipotesis dalam penelitian ini dilakukan dengan teknik analisis Partial Least Square (PLS) dengan program smart PLS 3.0. Pada statistik PLS analisis dilakukan menjadi dua langkah yaitu evaluasi pengukuran model (outer model / measurement model) dan evaluasi struktur model (inner model) untuk pengujian hipotesis. $^{4}$

\section{Evaluasi Outer Model}

Evaluasi ini bertujuan untuk menunjukkan hubungan antara variabel laten atau konstruk dengan indikator-indikator sebagai refleksi dari konstruk yang mendasarinya dan merupakan pengujian validitas dan reliabilitas indikator yang mempresentasikan setiap konstruk. Ada tiga penilaian dalam menilai hasil model pengukuran atau outer model yaitu :

\section{1). Uji Convergen Validity}

Penilaian convergent validity
digunakan untuk memastikan bahwa indikator yang digunakan dalam penelitian ini mampu dipahami oleh responden atau valid. Dalam evaluasi outer model ini dicari nilai outer loading atau loading factor dari masing-masing indikator untuk menentukan convergent validity .Bila nilai outer loading $>0,7$ maka indikator termasuk mempunyai convergent validity dengan kategori baik . Nilai outerloading dari indikator pada variabel penelitian ini sebagian besar mempunyai nilai outerloading $>0,7$. Tetapi masih ada beberapa indikator yang memiliki nilai outer loading $<0,7$. Chin menyatakan dalam Ghozali bahwa nilai outer loading antara 0,5 - 0,6 sudah dianggap cukup dan memenuhi syarat convergent validity. ${ }^{4}$ Hasil analisis data juga menunjukkan bahwa tidak ada nilai outer loading $<0,5$ sehingga semua indikator dianggap valid dan dapat dipakai dalam penelitian dan dapat dianalisis lebih lanjut.

\section{2) Discriminant Validity}

Penilaian discriminant validity dilakukan untuk memastikan bahwa setiap indikator dari masing-masing variabel laten berbeda dengan variabel lainnya. Penilaian discriminant validity menggunakan nilai average variant extracted (AVE) untuk masing-masing indikator. Untuk model discriminant validity yang baik dipersyaratkan nilai AVE harus $>0,5$.

\begin{tabular}{|c|c|}
\hline Variabel & AVE \\
\hline Tangibles & 0,708 \\
\hline Responsiveness & 0,715 \\
\hline Reliability & 0,149 \\
\hline Assurance & 0,487 \\
\hline Emphaty & 0,517 \\
\hline Kepuasan & 0,693 \\
\hline
\end{tabular}

Berdasarkan data dalam tabel 8 dapat dilihat bahwa nilai AVE sebagian besar variabel $>0,5$. Hanya variabel reliability dan assurance yang nilai AVE $<0,5$ sehingga dapat dikatakan bahwa dari keenam variabel dalam model ini terdapat empat variabel yang telah memiliki discriminant validity yang baik.

\section{3) Cronbach Alpha}

Uji realibilitas digunakan untuk menguji reliabilitas variabel untuk mengetahui konsistensi alat ukur. Untuk menguji raliabilitas Variabel pada analisa PLS dengan menggunakan nilai cronbach alpha. Variabel dapat dinyatakan reliabel bila mempunyai nilai cronbach alpha apabila memiliki nilai cronbach alpha $>0,7$. Nilai cronbach alpha dari masing-masing variabel dapat dilihat pada tabel 9.

Berdasarkan data pada tabel 9, dapat dilihat bahwa nilai cronbach alpha dari masing-masing variabel penelitian $>0,7$. Sehingga dapat dikatakan bahwa masing masing variable penelitian memiliki tingkat 
reliabilitas yang tinggi.

Tabel 9 Cronbach's Alpha

\begin{tabular}{lc}
\hline \multicolumn{1}{c}{ Variabel } & $\begin{array}{c}\text { Cronbach's } \\
\text { Alpha }\end{array}$ \\
\hline Tangibles & 0,940 \\
Responsiveness & 0,899 \\
Reliability & 0,743 \\
Assurance & 0,811 \\
Emphaty & 0,728 \\
Kepuasan & 0,910 \\
\hline
\end{tabular}

\section{Evaluasi Inner Model}

Pada evaluasi inner model akan dinilai uji path coefficient, uji kebaikan model (goodness of fit) dan uji hipotesis.

\section{1) Uji Path Coefficient}

Penilaian uji path coefficient adalah menilai kekuatan pengaruh variabel bebas terhadap variabel terikat. Penilaian coefficient determination (R-Square atau $\mathrm{R}^{2}$ ) dipakai untuk menilai seberapa besar variabel terikat atau variabel endogen dipengaruhi oleh variabel lainnya. Menurut Chin bila $\mathrm{R}^{2}>$ atau sama dengan 0, 974 menunjukkan bahwa pengaruh variabel bebas (variabel eksogen) terhadap variabel terikat (variabel endogen) termasuk dalam kategori baik. Jika nilai $\mathrm{R}^{2}$ antara $0,33-0,67$ termasuk dalam kategori sedang, dan jika $\mathrm{R}^{2}$ sebesar 0,19 0,33 termasuk dalam kategori lemah. ${ }^{4}$ Dapat dikatakan bahwa jika nilai path coefficient pada satu variabel independen terhadap variabel dependen semakin besar, maka pengaruh antara variabel independen terhadap variabel dependen tersebut semakin kuat.

\section{2). Uji Kebaikan Model (Goodness of Fit)}

Dari hasil pengolahan data dengan program smartPLS 3.0, didapatkan nilai $R$ Square sebagaimana terlihat pada table 10.

Tabel 10 Nilai R-Square

\begin{tabular}{cc}
\hline Variabel & $R$-Square \\
\hline Kepuasan pasien & 0,686 \\
\hline
\end{tabular}

Berdasarkan data pada tabel 10 di atas, dapat diketahui bahwa :

Kepuasan pasien yang dapat dijelaskan oleh konstruk tangible, reliability, responsiveness, assurance dan emphaty sebesar 68,6 \% sedangkan 31,4 \% dijelaskan oleh variabel lain diluar yang diteliti.

\section{3). Uji Hipotesis}

Berdasarkan analisis data pada penelitian ini bisa dilihat nilai T-Statistics dan nilai $P$-Values untuk pengujian hipotesis . Apabila T-statistics $\geq \mathrm{T}$ tabel $(1,96)$ maka Ho ditolak dan hipotesis penelitian diterima. Hipotesis penelitian juga bisa diterima apabila nilai $P$-Values $<0,05$. Nilai $P$-Values dapat dilihat pada Tabel 11.

\begin{tabular}{lc}
\multicolumn{2}{c}{ Tabel 11 Nilai P-values } \\
\hline \multicolumn{1}{c}{ Variabel } & P-Values \\
\hline Tangibles $=>$ Kepuasan Pasien & 0,003 \\
Responsiveness =>Kepuasan Pasien & 0,003 \\
Reliability $=>$ Kepuasan Pasien & 0,012 \\
Assurance $=>$ Kepuasan Pasien & 0,139 \\
Emphaty $=>$ Kepuasan Pasien & 0,001 \\
\hline
\end{tabular}

Berdasarkan nilai P-Values dan uji hipotesis pada tabel 11 dan 12, dapat dilihat bahwa dari lima hipotesis dalam penelitian ini, ada empat hipotesis yang dapat diterima karena hubungan antara variabel eksogen terhadap variabel endogen memiliki nilai P-Values $<0,05$ dan nilai $\mathrm{T}$ Statistik $>1,96$ ( T Tabel) sehingga dapat dikatakan terdapat pengaruh yang signifikan antara variabel independen terhadap variabel dependen. Hanya ada satu hipotesis yang ditolak yaitu variabel assurance terhadap kepuasan pasien yang nilai $P$ Values $>0,05$ dan T Statistik $<1,96$ sehingga dapat dinyatakan tidak ada pengaruh yang signifikan antara variabel independen (assurance) terhadap variabel dependen (kepuasan).

Tabel 12 Hasil Pengujian Hipotesis 


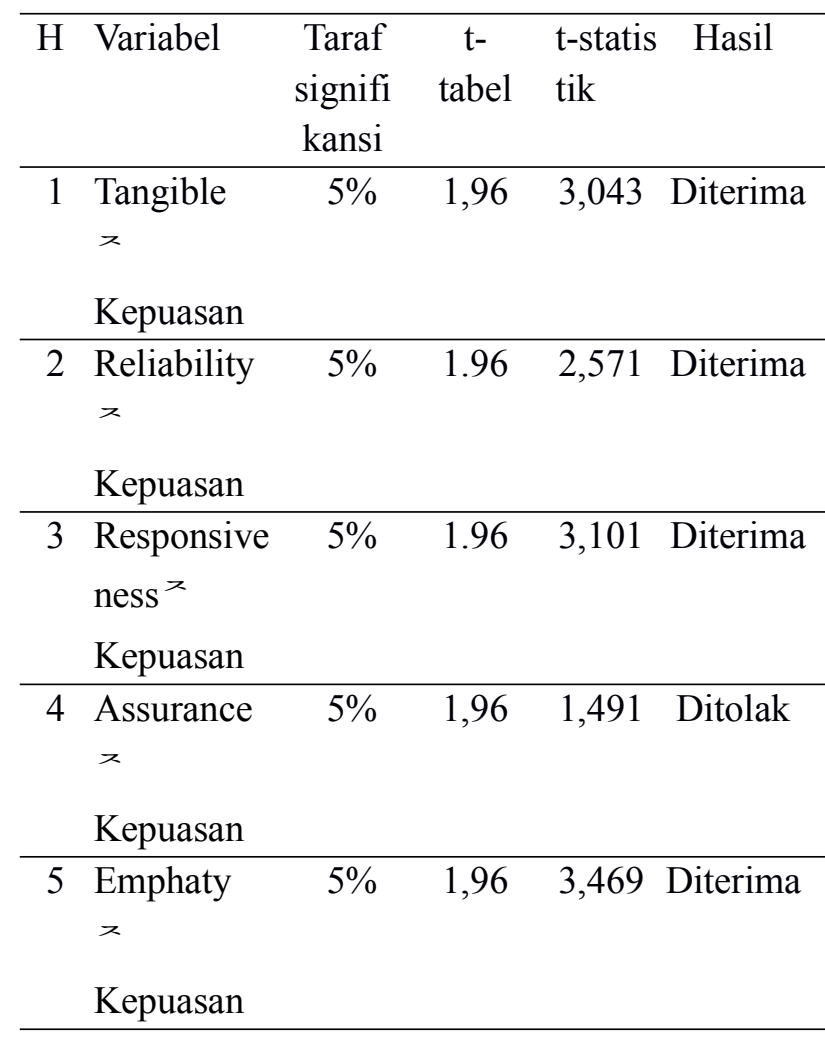

\section{Pembahasan}

\section{Pengaruh Tangible terhadap Kepuasan Pasien}

Dari pengujian hipotesis, didapatkan

bahwa nilai P-Values antara variabel tangibles terhadap Kepuasan Pasien adalah sebesar $0,003<0,05$ ditambah dengan nilai T-Statistics 3,043 > T Tabel (1,96), sehingga dinyatakan Tangibles berpengaruh signifikan terhadap Kepuasan Pasien.

Hal ini sejalan dengan penelitian Parasuraman dan A. Valerie (2001) bahwa tangible dalam kualitas pelayanan adalah bentuk realitas fisik yang dapat dimanfaatkan dan dirasakan oleh pelanggan dalam pelayanan yang diterima sehingga merasa puas. Dalam memanfaatkan pelayanan, pelanggan menginginkan fasilitas pelayanan yang terbaik dan dapat merasakan manfaat dari bukti fisik yang diberikan oleh rumah sakit, sehingga pelayanan memberikan kepuasan kepada pasien. ${ }^{5}$ Riset Dabholkar (1996) mengatakan bahwa fasilitas fisik dan rasa nyaman yang ditunjukkan kepada pelanggan berhubungan dengan tampilan fasilitas fisik. ${ }^{6}$ Hal ini didukung oleh penelitian Irchas Eko Wilantara (2015) yang mengatakan bahwa terdapat hubungan bermakna antara tangibles terhadap kepuasan pasien peserta BPJS kesehatan pada Pelayanan di Rawat Jalan Tingkat Pertama di Kota Bandar Lampung ${ }^{7}$. Begitu juga hal ini sejalan dengan penelitian Nurfardiansyah Burhanuddin (2015) yang mengatakan bahwa terdapat hubungan antara tangible dengan kepuasan Pasien peserta BPJS di Rawat Inap RSUD Syekh Yusuf Gowa ${ }^{8}$.

Dari hasil analisis deskriptif tentang tanggapan responden pada indikator dimensi kualitas pelayanan tangibles hal - hal yang prioritas perlu diperhatikan dan ditingkatkan oleh managemen Rumah Sakit adalah sebagai berikut :

- Tempat duduk pasien masih kurang

- Alat antrian belum optimal fungsinya

- Kebersihan toilet kurang.

Hal - hal tersebut harus segera ditindaklanjuti manajemen RS karena termasuk indikator tangibles yang akan berpengaruh signifikan terhadap kepuasan pasien peserta BPJS Kesehatan di IRJA RSUD dr. H. Soewondo Kendal.

\section{Pengaruh Reliability terhadap Kepuasan Pasien}

Dari pengujian hipotesis, didapatkan bahwa nilai P-Values antara variabel Reliability terhadap Kepuasan Pasien adalah sebesar 0,012<0,05 ditambah dengan nilai T-Statistics 2,571 > t table (1,96) sehingga dinyatakan Reliability berpengaruh signifikan terhadap Kepuasan Pasien.

Reliability atau keandalan adalah kemampuan rumah sakit untuk memberikan pelayanan yang handal, cepat dan akurat. Hal ini sejalan dengan penelitian Parasuraman dan A. Valerie (2001) bahwa reliability dalam 
kualitas pelayanan adalah bentuk pelayanan yang handal dan cepat kepada pelanggan sehingga merasa puas .Hal ini didukung oleh penelitian Irchas Eko Wilantara (2015) yang mengatakan bahwa terdapat hubungan bermakna antara reliability terhadap kepuasan pasien peserta BPJS kesehatan pada Pelayanan Rawat Jalan Tingkat Pertama di Kota Bandar Lampung. Begitu juga hal ini sejalan dengan penelitian Nurfardiansyah Burhanuddin (2015) yang mengatakan bahwa terdapat hubungan antara reliability dengan kepuasan Pasien peserta BPJS di Rawat Inap RSUD Syekh Yusuf Gowa.

Dari hasil analisis deskriptif tentang tanggapan responden pada indikator dimensi kualitas pelayanan reliability hal - hal yang prioritas perlu diperhatikan dan ditingkatkan oleh managemen Rumah Sakit adalah sebagai berikut :

- Dokter belum datang tepat waktu

- Kerahasiaan medis perlu lebih dijaga

- Petugas pendaftaran kurang ramah

- Perawat kurang ramah

- Petugas kurang cekatan.

Hal - hal tersebut harus segera ditindaklanjuti manajemen RS karena termasuk indikator reliability yang akan berpengaruh signifikan terhadap kepuasan pasien peserta BPJS Kesehatan di IRJA RSUD dr. H. Soewondo Kendal.

\section{Pengaruh Responsiveness terhadap Kepuasan Pasien}

Dari pengujian hipotesis, didapatkan bahwa nilai P-Values antara variabel Responsiveness terhadap Kepuasan Pasien adalah sebesar $0,003<0,05$ ditambah dengan nilai T-Statistics 3,101 > t tabel $(1,96)$, sehingga dinyatakan Responsiveness berpengaruh signifikan terhadap Kepuasan Pasien.

Hal ini sejalan dengan penelitian
Parasuraman dan A. Valerie (2001) bahwa responsiveness dalam kualitas pelayanan adalah respon cepat atau daya tanggap petugas terhadap keluhan dan kebutuhan pasien rumah sakit, sehingga pelayanan yang diberikan memberikan kepuasan kepada pasien. Hal ini juga sejalan dengan penelitian Irchas Eko Wilantara (2015) yang mengatakan bahwa terdapat hubungan bermakna antara responsiveness terhadap kepuasan pasien peserta BPJS kesehatan pada Pelayanan Rawat Jalan Tingkat Pertama di Kota Bandar Lampung. Begitu juga hal ini sejalan dengan penelitian Nurfardiansyah Burhanuddin (2015) yang mengatakan bahwa terdapat hubungan antara responsiveness dengan kepuasan Pasien peserta BPJS di Rawat Inap RSUD Syekh Yusuf Gowa.

Dari hasil analisis deskriptif tentang tanggapan responden pada indikator dimensi kualitas pelayanan responsiveness hal - hal yang prioritas perlu diperhatikan dan ditingkatkan oleh managemen Rumah Sakit adalah sebagai berikut :

- Petugas pendaftaran kurang tanggap terhadap pasien

- Perawat kurang perhatian kepada pasien

- Petugas belum memberikan informasi secara aktif

- Perawat kurang tanggap terhadap pasien. Hal - hal tersebut harus segera ditindaklanjuti managemen RS karena termasuk indikator responsiveness yang akan berpengaruh signifikan terhadap kepuasan pasien peserta BPJS Kesehatan di IRJA RSUD dr. H. Soewondo Kendal.

\section{Pengaruh Assurance terhadap Kepuasan Pasien}

Dari pengujian hipotesis, didapatkan bahwa nilai P-Values antara variabel Assurance terhadap Kepuasan Pasien adalah sebesar 0,139>0,05 ditambah dengan nilai 
T-Statistics $1,491<\mathrm{t}$ tabel $(1,96)$ sehingga dinyatakan Assurance tidak berpengaruh signifikan terhadap Kepuasan Pasien.

Assurance atau jaminan adalah kompetensi atau kemampuan yang dimiliki rumah sakit sehingga membuat pasien merasa aman, bebas resiko. Jaminan termasuk kepastian pelayanan tentang prosedur dan perilaku petugas. Hal ini tidak sejalan dengan penelitian Parasuraman dan A. Valerie (2001) bahwa assurance dalam kualitas pelayanan adalah jaminan dan kepastian pelayanan yang dirasakan pasien rumah sakit, sehingga pelayanan yang diberikan memberikan kepuasan kepada pasien. Hal ini juga tidak sejalan dengan penelitian Irchas Eko Wilantara (2015) yang mengatakan bahwa terdapat hubungan bermakna antara assurance terhadap kepuasan pasien peserta BPJS kesehatan pada Pelayanan Rawat Jalan Tingkat Pertama di Kota Bandar Lampung. Begitu juga hal ini tidak sejalan dengan penelitian Nurfardiansyah Burhanuddin (2015) yang mengatakan bahwa terdapat hubungan antara assurance dengan kepuasan Pasien peserta BPJS di Rawat Inap RSUD Syekh Yusuf Gowa.

Peneliti menduga hal ini bisa terjadi karena pasien peserta BPJS Kesehatan di Kabupaten Kendal yang diwakili responden sudah merasa nyaman atau menerima semua pelayanan di rawat jalan yang berhubungan dengan dimensi assurance atau jaminan sehingga hal ini tidak mempengaruhi tanggapan responden terhadap kualitas pelayanan .

Dari hasil analisis deskriptif tentang tanggapan responden pada indikator dimensi kualitas pelayanan assurance hal - hal yang prioritas perlu diperhatikan dan ditingkatkan oleh managemen Rumah Sakit adalah sebagai berikut :

- Masih ada diskriminasi pasien

- Pengecekan pasien dengan benar kurang diperhatikan

- Petugas kurang jelas dalam menjelaskan informasi kepada pasien.

Hal - hal tersebut harus segera ditindaklanjuti managemen RS meskipun indikator assurance pada penelitian ini tidak berpengaruh signifikan terhadap kepuasan pasien peserta BPJS Kesehatan di IRJA RSUD dr. H. Soewondo Kendal.

\section{Pengaruh Emphaty terhadap Kepuasan Pasien}

Dari pengujian hipotesis, didapatkan bahwa nilai P-Values antara variabel Emphaty terhadap Kepuasan Pasien adalah sebesar 0,001<0,05 ditambah dengan nilai T-Statistics 3,469 > t tabel $(1,96)$ sehingga dinyatakan Emphaty berpengaruh signifikan terhadap Kepuasan Pasien.

Hal ini sejalan dengan penelitian Parasuraman dan A. Valerie (2001) bahwa emphaty dalam kualitas pelayanan adalah perhatian dan pelayanan istimewa yang dirasakan pasien rumah sakit, sehingga pelayanan yang diberikan memberikan kepuasan kepada pasien. Hal ini didukung dengan penelitian Irchas Eko Wilantara (2015) yang mengatakan bahwa terdapat hubungan bermakna antara emphaty terhadap kepuasan pasien peserta BPJS kesehatan pada Pelayanan Rawat Jalan Tingkat Pertama di Kota Bandar Lampung. Begitu juga hal ini sejalan dengan penelitian Nurfardiansyah Burhanuddin (2015) yang mengatakan bahwa terdapat hubungan antara emphaty dengan kepuasan Pasien peserta BPJS di Rawat Inap RSUD Syekh Yusuf Gowa.

Dari hasil analisis deskriptif tentang tanggapan responden pada indikator dimensi kualitas pelayanan emphaty hal - hal yang 
prioritas perlu diperhatikan dan ditingkatkan oleh managemen Rumah Sakit adalah sebagai berikut :

- Petugas pendaftaran kurang perhatian kepada pasien

- Perawat kurang perhatian kepada pasien

- Petugas kurang ramah.

Hal - hal tersebut harus segera ditindaklanjuti managemen RS karena termasuk indikator emphaty yang akan berpengaruh signifikan terhadap kepuasan pasien peserta BPJS Kesehatan di IRJA RSUD dr. H. Soewondo Kendal.

\section{Tanggapan Responden tentang Kepuasan Pasien}

Dari hasil analisis deskriptif tentang tanggapan responden secara umum pada variabel kepuasan menunjukkan bahwa pasien sudah merasa puas dalam hal biaya pelayanan, informasi petugas, fasilitas rumah sakit dan perawatan petugas. Hal - hal yang prioritas perlu diperhatikan dan ditingkatkan oleh manajemen Rumah Sakit karena pasien masih kurang puas adalah dalam hal waktu tunggu yang lama dan sikap petugas.

Hal - hal tersebut harus segera ditindaklanjuti manajemen RS untuk meningkatkan kepuasan pasien peserta BPJS Kesehatan di IRJA RSUD dr. H. Soewondo Kendal.

\section{KESIMPULAN}

Hasil penelitian menunjukkan terdapat pengaruh antara Tangible (Bentuk Fisik), Reliability (Kehandalan), Responsiveness (Daya tanggap) dan Emphaty (Perhatian) terhadap Kepuasan pasien peserta BPJS Kesehatan di Instalasi Rawat Jalan RSUD dr. H. Soewondo Kendal. Sedangkan variabel Assurance (Jaminan) tidak berpengaruh terhadap Kepuasan pasien peserta BPJS Kesehatan di Instalasi Rawat Jalan RSUD dr.
H. Soewondo Kendal.

\section{UCAPAN TERIMAKASIH}

Penulis mengucapkan terima kasih kepada MIKM FKM UNDIP dan RSUD dr. H. Soewondo Kendal atas diijinkannya melakukan penelitian ini.

\section{DAFTAR PUSTAKA}

1. Depkes RI. Undang-Undang Nomor 44 Tentang Rumah Sakit. 2009.

2. Anonim. Laporan Indeks Kepuasan Masyarakat RSUD dr. H. Soewondo Kendal. 2015

3. Kotler, P. and K.L. Kelller. Marketing Managemen. $14^{\text {th }}$ ed. Prentice Hall International,Inc; 2012.

4. Ghozali, Imam. Sructural Equation Modelling. Metode Alternatif dengan Partial Least Squares (PLS). Edisi 4. Semarang : Badan Penerbit Universitas Diponegoro ; 2014.

5. Parasuraman, A., Berry, Leonard L, and Zeithaml, Valarie A. A Conceptual Model of Service Quality and Its Implications for Future Research. Journal of Marketing, 1985; Vol 49 ; 4150 .

6. Dabhokar, J.O Rentz. A Measure of Service Quality for Retail Stores: Scale Development and Validation. Journal of The Academy of Marketing Science. 1996 ; Vol. 24 ; 3 - 16.

7. Eko W, Irchas . Analisis Kepuasan Pasien Peserta BPJS Kesehatan Pada Pelayanan Rawat Jalan Tingkat Pertama (RJTP) di Kota Bandar Lampung (Skripsi). Universitas Sriwijaya ; 2015.

8. Burhanudin, Nurfardiansyah. Hubungan Mutu Pelayanan Kesehatan dengan Kepuasan Pasien Peserta BPJS di Rawat 
Inap RSUD Syekh Yusuf Gowa (Skripsi).

Universitas Hasanudin ; 2015. 